\title{
IMPACTS OF CLIMATE DANGER ON COTTON PRODUCTION IN THE SECOND AGRICULTURAL DEVELOPMENT POLE IN NORTH BENIN
}

\author{
Cyr Gervais ETENE, Patrice Maximilien BOKO and Audry AMOUSSOU \\ Department of Geography and Regional Planning, University of Abomey-Calavi, Republic of Benin \\ Pierre Pagney Laboratory: Climate, Water, Ecosystems and Development (LACEEDE), University of Abomey \\ Calavi, B.P 526, Cotonou Republic of Benin \\ https://doi.org/10.35410/IJAEB.2021.5605
}

\begin{abstract}
"Climate dereglement and cotton production in Kandi district in Northern Benin" Cotton production is one of theagricultural sub-sectors potentially affected by the variability of climate patterns in West Africa. This study analyzes the incidences of climate variability on cotton cultivation in the district of Kandi. This analysis is based on climate data (rainfalland temperature) for the period 1971-2015 and statistics of area and yield of cotton production on the period 1995-2010. The pluviometric anomalies vary between -2.21 to +2.64 and the temperatures from - 1.59 to 2.20 .

The various treatments of quantitative data were reinforced by socio-anthropological qualitative data from fieldwork. The results reveal unimodal rainfall with a rainy season (May to October) and a dry season (November to April). The annual change in rainfall over the period 1971-2015 shows an upward trend marked by $48 \%$ of deficit, $3 \%$ of average and $49 \%$ of surplus years. The problem in the district of Kandi is related to changes in precipitation. In addition, the average temperature has increased by $1.9^{\circ} \mathrm{C}$. All these parameters affect cotton production and performance. The traditional agricultural calendar is subject to disruption according to climatic variations. In response, farmers are developing several coping strategies to cope with the impacts to which they are subject. These results may be useful in the context of accompanying policies that could help improve the well-being of common farming.
\end{abstract}

Keywords: Climate Variability, Cotton Production, Adaptation Strategy, Kandi District.

\section{INTRODUCTION}

The global climate has entered into an evolution without analogy with regard to the data available on the climate of the last two millennia. The tropical climatic space has known for several decades a persistence of climatic extremes (IPCC, 2014). This variability manifests itself by more or less random anomalies and crises and reveals successive or alternative phases of water surpluses and deficits (C. Houndénou and Hernandez, 1998). According to E. Ogouwale (2006), the decrease in rainfall, the reduction in the length of the agricultural season, the persistence of anomalies, the increase in average temperatures, now characterize the climates of Benin and modify the rainfall patterns and agricultural production systems. . The northern region of the country, since 1958, 1977 and 1983, has suffered the greatest rainfall deficit with a 
generalization of drought and a constant drop in the number of rainy days in the various stations (M. Boko et al., 1999). The shortening of the only rainy season that normally characterizes the region leads to a delay in the onset of rainy events (C. Houndénou, 1999). The aim of this work is to analyze the regime or rhythm of climatic parameters and their influences on cotton production from May to September in the commune of Kandi.

1. Presentation of the study environment

The present study was carried out in the commune of Kandi, in the North-East of Benin (fig. 1). It is located in the center of the department of Alibori, in agro-ecological zone $\mathrm{n}^{\circ} 2$ (Cotton zone of North Benign). Located between $10^{\circ} 55$ "and $11^{\circ} 39^{\prime \prime}$ North latitude and $2^{\circ} 38$ "and $3^{\circ} 15^{\prime \prime}$ East longitude, it covers an area of $3,421 \mathrm{~km}^{2}$; or $13 \%$ of the entire department.

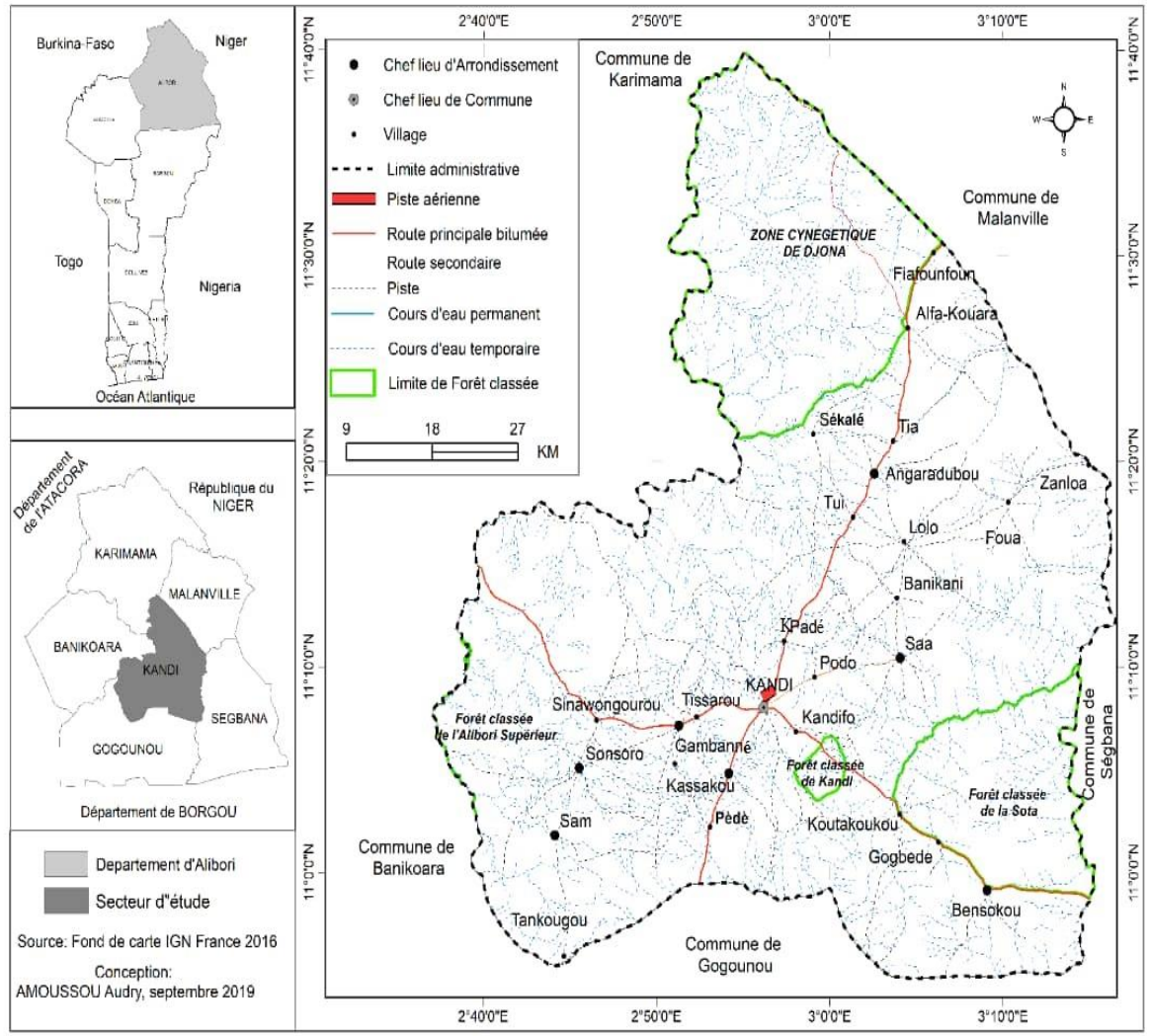

\section{DATA AND DATA PROCESSING METHODS}

\subsection{Data used}

Two types of data were used in this study. First, monthly rainfall data was mobilized from ASECNA (Agency for the Safety of Air Navigation in Africa and Madagascar), over the period from 1971 to 2015. 
Second, statistics on the development of area and cotton production yield are taken from the FAO database (2014), available online (FAOSTAT). All these data were supplemented by a field survey from 10 to 29 November 2019. A total of 179 households out of 215 agricultural households were surveyed in the municipality on the basis of a sample determined according to the probabilistic theory of Schwartz (1995). households were selected at random from the villages of the commune.

\subsection{Data processing method}

The processing of climatic parameters (temperature and rainfall) and field data is based on the use of the Excel 2007 tool and tests. This made it easier to process the data and make various diagrams. The Pettitt test was used to determine the series of rainfall heights in order to specify the position of the inflection point marking a possible break. When the null hypothesis (Ho) is accepted, we deduce that there is no break in the series (Xi) of size N. On the contrary, Dumolard and Charleux (2005) think that if the hypothesis is rejected, we conclude with an estimate of the break date by considering the maximum absolute value observed in the series (Xi). The implementation of the test supposes that for any instant $t$ included between 1 and $\mathrm{N}$, the chronological series $(\mathrm{Xi}) \mathrm{i}=1$ a t and $\mathrm{t}+1$ a $\mathrm{N}$ belong to the same population. This test is based on the calculation of the variable Ut, ndefined by:

$$
U_{i, N}=\sum_{i=1}^{1} \sum_{j=t+1}^{N} D_{i j}
$$

Où $\operatorname{Dij}=\operatorname{sgn}(X i-x j$ avec $\operatorname{sgn}(Z)=1$ si $Z>0 ; 0$ si $Z=0$ et $-1 \operatorname{si~} Z<O$.

et $\mathrm{KN}$ be the variable defined by the maximum in absolute value of $\mathrm{Ut}, \mathrm{n}$ for $\mathrm{t}$ varying from $\mathrm{n}$ to $\mathrm{n}-1$, if Kmax denotes the value of Kn taken for the series studied, under the null hypothesis, the probability of exceeding the Kmax value is given approximately by:

For a given risk of the first kind, if the probability Prob ( $\mathrm{KN}>\mathrm{Kmax}$ ) is influenced by $\square$, the null hypothesis is rejected.

The agro-climatic analysis method of the water balance in tropical regions developed by Franquin (1969) was used to determine the position of precipitation and the ETP.

\section{RESULTS AND DISCUSSION}

\subsection{Climate indicators in the municipality of Kandi}

\subsubsection{Rainfall indicators in the municipality of Kandi}

The rainfall regime in Kandi commune is unimodal with two well-marked seasons: a rainy season from May to October and a dry season from November to April. 
Figures 2 and 3 show the climate balance of precipitation in Kandi and the inter-annual rainfall variability of precipitation in Kandi commune.

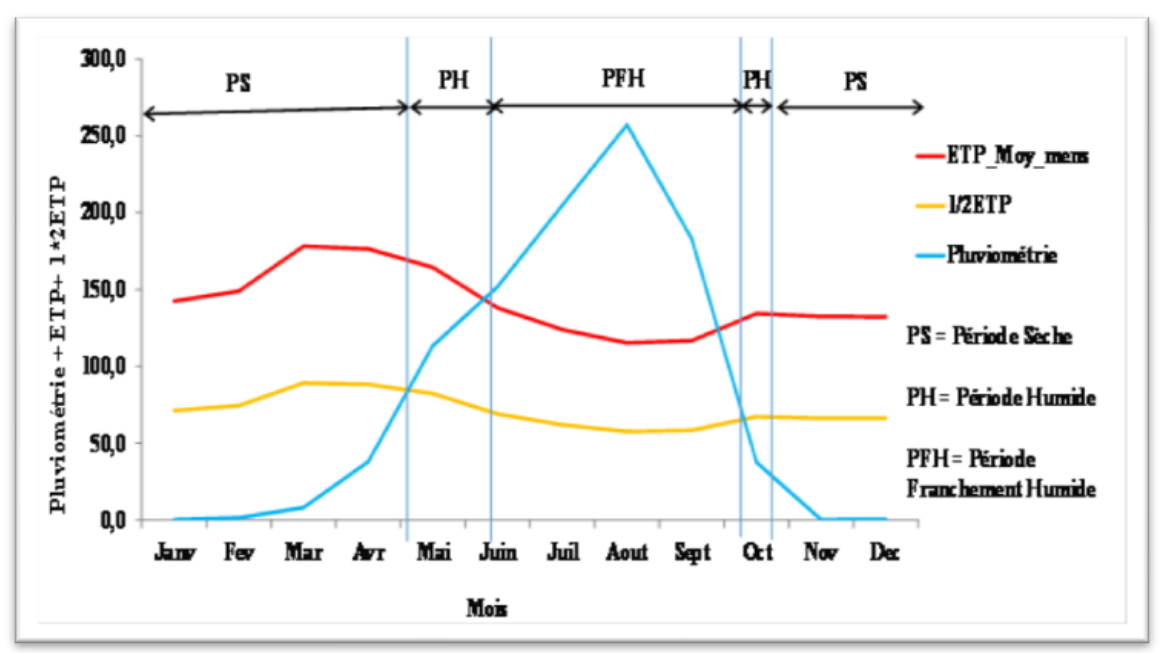

Figure 2: Climate balance of the Kandi

Data source: ASECNA, 2015

The pre-wet period (soil moisture is still insufficient) lasts 4 decades and corresponds to the time of soil preparation and the first sowing. The wet period when the soils are wet corresponds to the period of growth and maturation of crops which meet the water requirement. During this period, the farmers carry out maintenance work (weeding, spreading fertilizer, phytosanitary treatment). It lasts 15 decades in the town of Kandi and normally allows the crop cycle to be fully completed.

The post-humid period corresponds to the first harvests. It lasts 2 decades.

As for the dry period which lasts 10 decades, it is the moment when the peasants finish the harvest and store the products. This period corresponds to the rest periods of the peasants who take advantage of it to perform ritual ceremonies. It also coincides with the end of the year celebrations. 


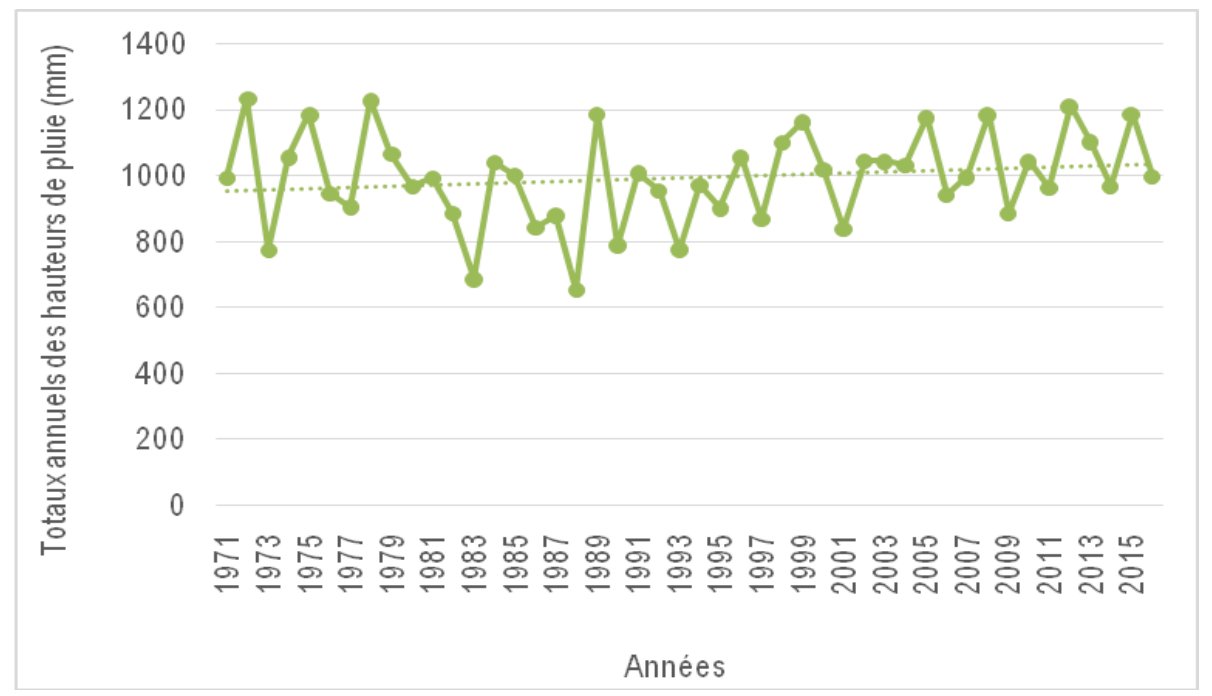

Figure 3. Inter-annual rainfall variability over the period 1971-2015

The analysis of Figure 3 shows an interannual variability of precipitation in the Municipality of Kandi between 1971 and 2015. Thus, the decade 1971-2000 is characterized by an upward trend in rainfall amounts. On the other hand, the decade 1981-1990 shows a downward trend in rainfall amounts with an average of $1000 \mathrm{~mm}$ and finally the decades 2001-2015 are rather characterized by an increasing resumption of rainfall in the study environment. This variation has a dangerous impact on agrosystems, because this agricultural area is dependent on rains.

\subsubsection{Thermal indicators in the municipality of Kandi}

The monthly and annual average temperatures over the period 1971-2015, helped determine the rate of change in the average temperature in the commune of Kandi. Figure 4 shows the evolutionary tendency for the temperature to rise in Kandi.

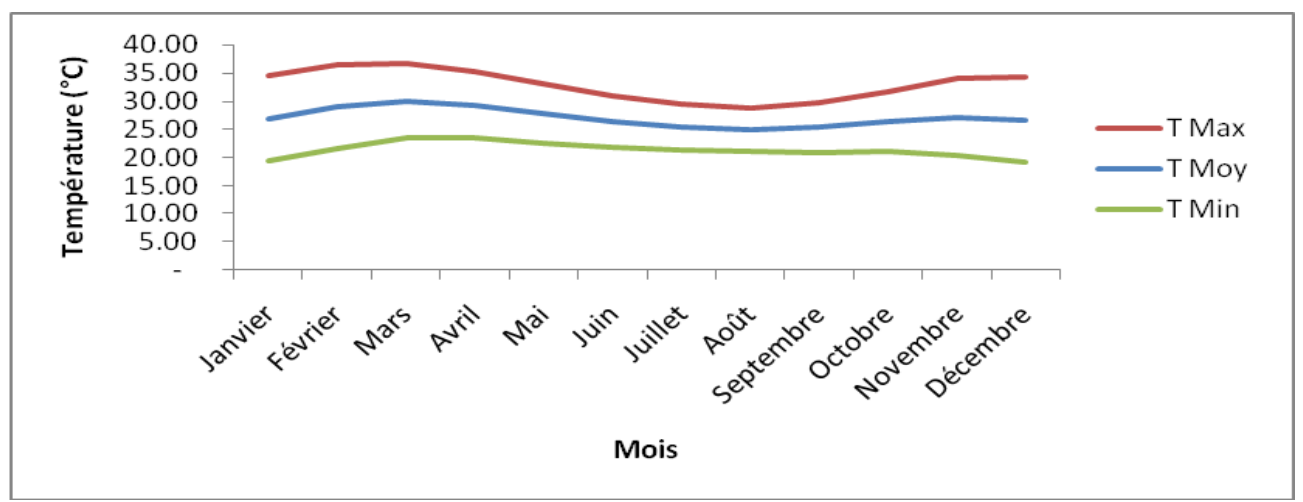

Figure 4. Average monthly temperature regime for 1971-2015 
The hot period concerns the months of February to April when temperatures reach $37^{\circ} \mathrm{C}$. This period is dangerously influencing speculations in Kandi. As for the cool period, it concerns the months of November to January when temperatures can drop to $16^{\circ} \mathrm{C}$ in the mornings during harmattan weather and the thermal amplitude relatively high due to the effect of continentality. This period is very favorable for the cultivation of cowpeas in the district of Angaradébou. The temperatures that are recorded during the agricultural season are not limiting for crops. They therefore find there good thermal conditions for their development.

\subsubsection{Detection of breaks in stationarity in the rainfall series of the Kandi station}

Figure 5 shows the breaks in stationarity in the rainfall series at the Kandi station
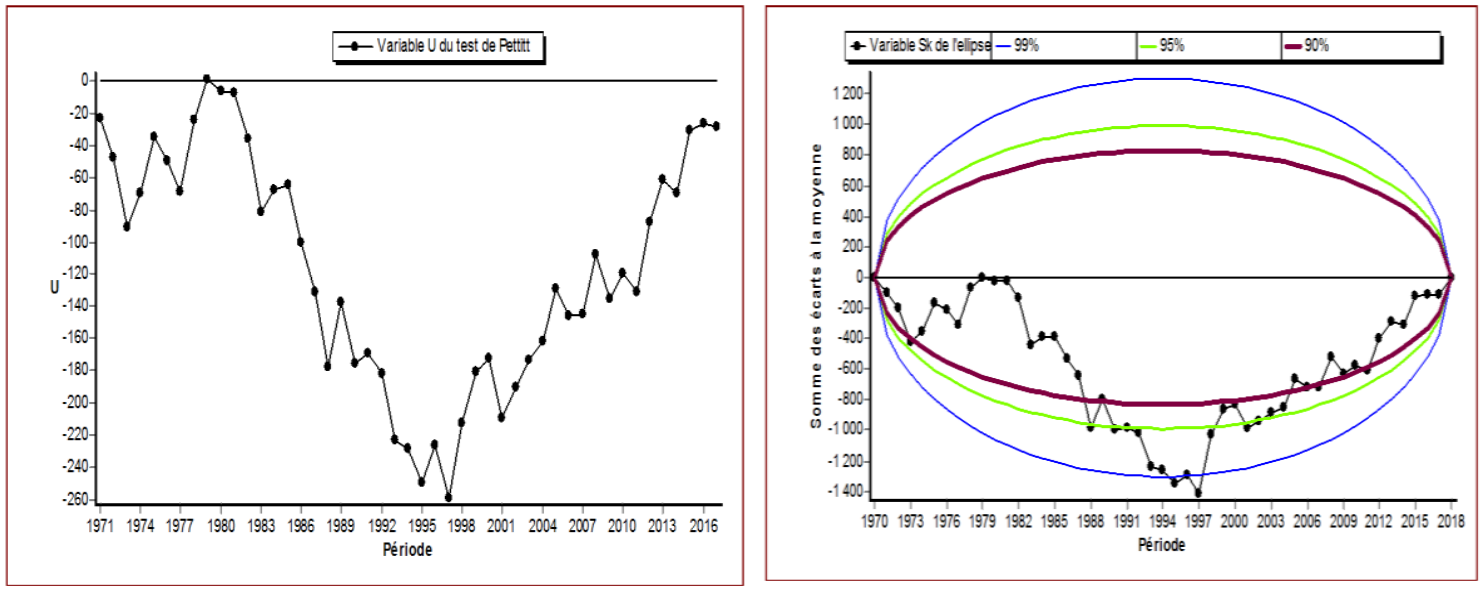

Figure 5: Analysis of the break in stationarity in the Kandi rainfall series from 1970 to 2018

It emerges from the analysis of FIG. 5 that a break in stationarity was observed during the years 1997 in the pluviometric field used with a significance of $99 \%$ according to the Pettitt test. There are therefore two major sub-periods, notably the wet period from 1971 to 1997 and the period of rainfall recession from 1998 to 2016. To better appreciate each sub-period, an analysis is made of the segmentation proposed by Hubert in the break in stationarity. Thus, Table I presents the sub periods according to Hubert's segmentation.

Table I: Hubert segmentation

\begin{tabular}{|c|c|c|c|}
\hline \multicolumn{2}{|c|}{ Période } & \multirow{2}{*}{ Moyenne } & Ecart type \\
\cline { 1 - 2 } Début & Fin & & \\
\hline $\mathbf{1 9 7 1}$ & $\mathbf{1 9 9 7}$ & 941,437 & 141,298 \\
\hline $\mathbf{1 9 9 8}$ & $\mathbf{2 0 1 6}$ & 1061,162 & 124,627 \\
\hline
\end{tabular}


Significance of the Scheffé test: $1 \%$

It emerges from the analysis of Table I that the sub-period 1971 to 1997 has an average of 941.43 and a deviation of 141.29 while the sub-period 1998 to 2016 requires an average of 1061.16 and a standard deviation of 124.62. This leads to say, according to Hubert's segmentation in the research of the break in stationarity, that the sub-period 1971 to 1997 is less humid than the sub-period 1998 to 2016. This result allows us to know that in a less humid period, the production is less whereas in the wet period, the production is greater.

\subsection{Evolution of yields and areas in relation to rainfall}

Of the $3,421 \mathrm{~km}^{2}$ area available to the municipality of Kandi, the area of cultivable land is approximately 2,400 $\mathrm{km}^{2}$. Cotton production contributes $39 \%$ to the Gross Domestic Agricultural Product (PIBA) and contributes more than $80 \%$ to Benin's export earnings (MAEP, 2019. Figure 6 shows the evolution of yields and cultivated areas in the commune of Kandi from 1995 to 2010 .

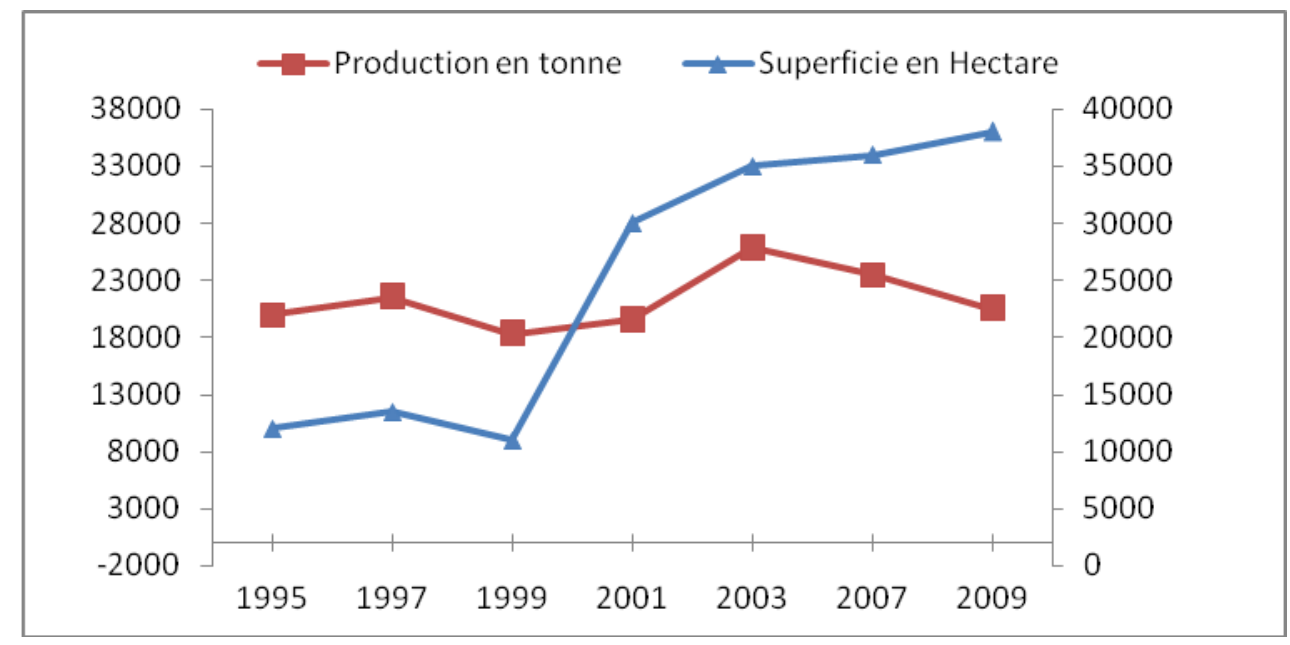

Figure 6. Evolution of yields, production and cultivated areas in the study environment

Source: FAOSTAT database, 2014

During the years 1995 to 2007, the commune of Kandi recorded an increase in yields of 28477t of cotton, i.e. 59.95\% of yields from 1995 to 2010. The yield recorded a decrease of 34801t or $73.26 \%$ from 2007 to 2010 The cultivated area also noted from 1995 to 2008, an increase of 22,694 ha or $62.01 \%$ of sown areas from 1995 to 2010 . Then a decline of 24,164 ha or $(66.03 \%)$, is recorded from 2008 to 2010 . Figure 7 correlates the annual rainfall with cotton production. 
Vol. 06, No. 01; 2021

ISSN: $2456-8643$

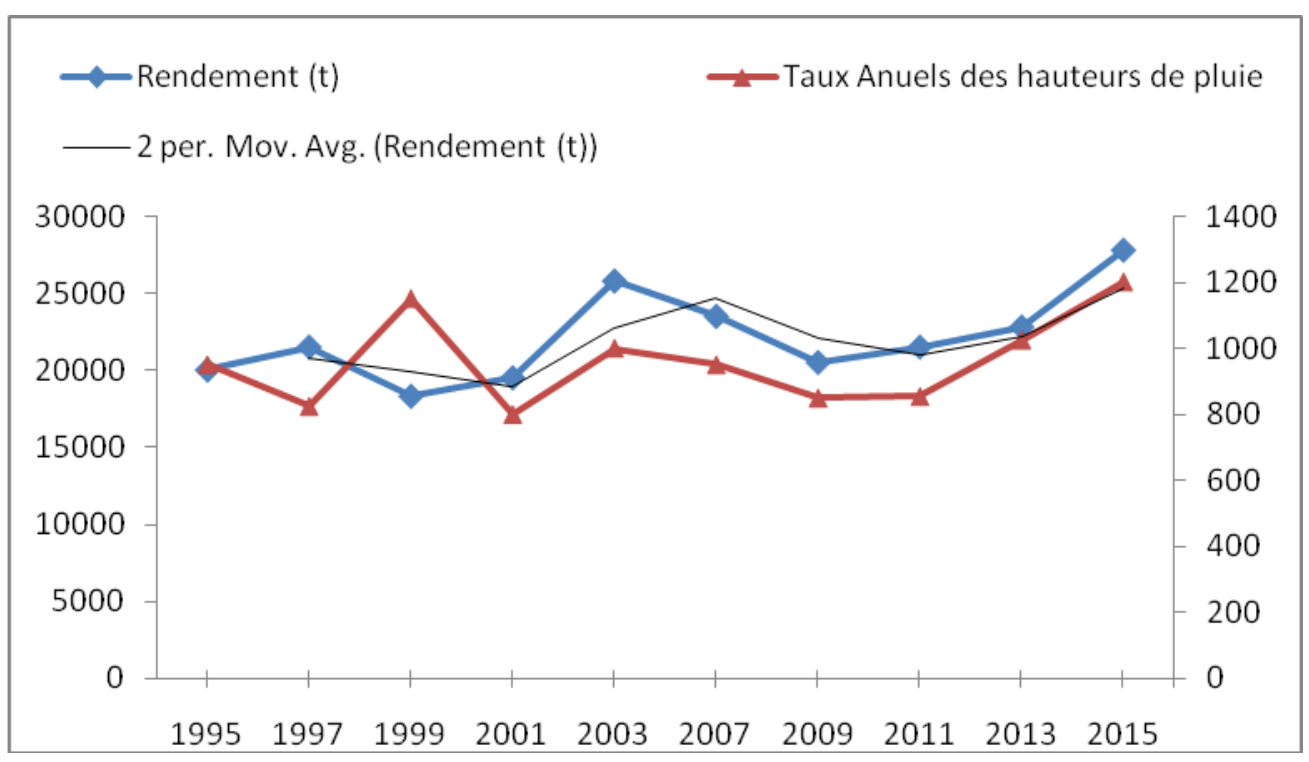

Figure 7: Correlation of annual rainfall amounts with cotton production

Analysis of Figure 7 reveals that rainfall in wet years 1998, 1999, 2005, 2008 and 2014 correlates positively with increased yields of cotton production. The availability of water favors cotton cultivation. Between 5,400 and 19,000 liters of water are needed to produce $1 \mathrm{~kg}$ of cotton (R. Bouchet, 1963). In kandi, the maximum amount of rainfall is around $1,100 \mathrm{~mm}$. rainfall deficit and probably the state of soil fertility and the improper use of agricultural fertilizers in production. Precipitation is a major factor in the cultivation and yield of cotton. Our results confirm those of Odjo (1997) who shows that the decrease in production is related to the quantity of precipitated water. For Ouorou Barre (2010), rainfall and temperature are not the only determining factors for a good yield, there is also the state of soil fertility which plays a determining role. Thus, according to M. Boko (1988), climatic fluctuations are at the origin of changes in cropping calendars. This position is also that of J. Vignigbé, (1992) who showed that the disturbance in cropping systems can be explained by rainfall irregularity, the poor spatiotemporal distribution of precipitation and especially the disruption of the agricultural calendar. E. Ogouwalé (2004) also showed that there is indeed a risk of reduced production yields in the different agro-ecological regions of Benin, when there is a further increase in temperatures and when the soils become drier.

\subsection{Producers' perception of climate variability and its impact on cotton production}

Table II presents the Synthesis on farmers' perceptions of climate change 
Table II: Summary of peasant perceptions of climate change

\begin{tabular}{|l|l|}
\hline $\begin{array}{l}\text { Climatic changes } \\
\text { Registered }\end{array}$ & Manifestations / consequences \\
\hline $\begin{array}{l}\text { late and / or poor } \\
\text { distribution of } \\
\text { rains }\end{array}$ & $\begin{array}{l}\text { po\% of respondents indicate that there has been a change in the } \\
\text { progress of the agricultural season. The rains are setting in } \\
\text { currently in the second ten days of May instead } \\
\text { April. }\end{array}$ \\
\hline Decreased heights & $\begin{array}{l}\text { Over the past fifteen (15) years, rainfall levels have decreased } \\
\text { compared to fifteen (15) years } \\
\text { previous according to 88.2\% of respondents. For the latter, the } \\
\text { rains decrease over the years. }\end{array}$ \\
\hline Decrease in the number of & $\begin{array}{l}\text { For } 80.8 \% \text { of respondents, the number of rainy days was } \\
\text { decreased over the last fifteen (15) years } \\
\text { compared to the previous fifteen. The rains are } \\
\text { concentrate on a short time and suddenly the cultures do not } \\
\text { not taking advantage of all the quantities of water that fell during } \\
\text { the } \\
\text { rainy season. }\end{array}$ \\
\hline Occurrence of winds & $\begin{array}{l}\text { When we go back thirty (30) years, the winds } \\
\text { violent were observed at the start of the rainy season and } \\
\text { had on average only two, causing the disheveled } \\
\text { roofs of houses; but these last fifteen (15) years the } \\
\text { strong winds are recorded both at the beginning and at the end of } \\
\text { the }\end{array}$ \\
\hline
\end{tabular}




\begin{tabular}{|l|l|}
\hline Excessive heat & rainy season and are more violent according to 92\% of respondents. \\
& $\begin{array}{l}\text { The times have gotten hotter, according to 99\% of } \\
\text { surveyed, and even under the trees the heat is unbearable. } \\
\text { Wilting of cultivated plants in fields is } \\
\text { exhibited as among others by the peasants as the } \\
\text { consequence of strong and persistent heat during } \\
\text { agricultural campaign. For them, cloudy weather has subsided } \\
\text { to the detriment of very sunny weather. }\end{array}$ \\
\hline Dryness pockets more & $\begin{array}{l}\text { Rain breaks during the season are more and more numerous over } \\
\text { the past fifteen (15) years and have resulted in crop losses according } \\
\text { to 92\% of those surveyed. The } \\
\text { periods when these pockets of drought are often observed } \\
\text { are May-June, July and end of September according to the } \\
\text { statements of peasants. }\end{array}$ \\
\hline $\begin{array}{l}\text { Occurrence of very heavy } \\
\text { and violent rains causing } \\
\text { damages }\end{array}$ & $\begin{array}{l}\text { The rains of the last fifteen (15) years are very } \\
\text { violent and accompanied by high winds whose } \\
\text { result of the demolition of houses according to 75\% of respondents }\end{array}$ \\
\hline Persistence of drought & $\begin{array}{l}\text { For 96\% of respondents, the drought extends over a period } \\
\text { longer from October to April instead of November to April. }\end{array}$ \\
\hline
\end{tabular}

Source: Field survey, September 2019

For the majority of producers surveyed (55\%), the persistence of climatic extremes is caused by human activities: deforestation, deforestation and vegetation fires. According to 95\% of respondents, the delay of the great rainy season, the irregularity of the rain, excessive heat and pockets of drought in the rainy season justify the drop in yield observed during the second period from 2007 to 2010 compared to the first. period from 1995 to 2007 (Figure 6). For the latter, the town has experienced cases of delay in the onset of rains, pockets of drought in the middle of the rainy season. These variations in the climate in the commune affect various stages of crop 
establishment (soil preparation, sowing, manuring, various maintenance), and also prevent the over-development of cotton plants. The cropping calendar must be readjusted according to the current rainfall cycle. The consequences are evidently revealed through the returns.

This perception of the cotton producers of Kandi corroborates the results of Ouorou Barre, (2010) who observed that the variability of climatic parameters upset the agricultural calendar in the commune. The poor use of agricultural inputs in relation to the recommendations of agricultural research and extension structures, lower soil fertility, poor quality of inputs and seeds determine the development of production (Chédé, 2013). These factors, which are not taken into account in the context of this study, should not be ignored. We can unequivocally confirm that climatic factors (rainfall and temperature) are not the only determinants of yields (Ouorou Barre, 2010).

\section{CONCLUSION}

Climate variability and its perception by the populations of the municipality are highlighted in this study. Cotton production and its profitability remain dependent on rainfall. In this context of uncertainty, farmers are developing several adaptation strategies that have not been presented in this paper. The detailed study of these strategies and the analysis of their level of effectiveness should be priorities for further study.

At the end of this study, we would like to especially thank the authorities of the Scientific Council for having financed this study through the "Vulnagrosy" project.

\section{REFERENCES}

Boko Michel., 1988: Climates and rural communities in Benin: climatic rhythms and rhythms of development, Doctoral thesis ès State, University of Burgundy, Dijon, 601 p.

Boko Michel., Kosmowski Ferdinand., VissinWilfried. Expedit., 2012: The Issues of Climate Change in Benin: Program for Political Dialogue in West Africa. Konrad-Adenauer-Stiftung, Cotonou, $65 \mathrm{p}$.

ChedeFrédérick., Houndenou Constant., Sarr Brice., Yabilbouraima., 2013: Climatic risks and agricultural activities in the commune of save: 159-163. In Boko Michel., VissinExpédit.Wilfried., Afoudafulgence., "Climate Agriculture, Water Resources from yesterday to tomorrow", Proceedings of the XXVIth AIC Colloquium, Benin, 573 p.

CodjoThiburce., Lamodi Fiacre., Agbalessi Saturnin., OgouwaleRomarick., OgouwaleEuloge., 2013: Farmer strategies for adaptation to climate change in the town of pobè: Proceedings of the XXVIth AIC Symposium, Benin, 573 p.

Dumolard Paul., Charleux Léon., 2005. Statistics in Geography. Belin, 240p.

Djenontin Abel., Dagbenonbakin Gabriel., Igue Michel., Azontonde Alfred., Mensah Guy, Appolinaire., 2012: Endogenous practices for enhancing crop residues in the management of soil fertility on farms in northern Benin. A technical sheet, INRAB, Benin, 9 p. 